\title{
Variation in size-at-age between native cutthroat and introduced brown trout in allopatry and sympatry: implications for competitive interaction
}

\author{
Josh E. Rasmussen ${ }^{1, *}$, Mark C. Belk ${ }^{1}$, Evelyn Habit ${ }^{2}$, Dennis K. Shiozawa ${ }^{1}$, \\ Richard D. Hepworth ${ }^{1}$, Adam Anthony ${ }^{1}$ \\ ${ }^{1}$ Department of Biology, Brigham Young University, Provo 84602, Utah, USA \\ ${ }^{2}$ Aquatic Systems Unit, Environmental Science Center Eula-Chile, University of Concepcion, Chile
}

\begin{abstract}
Brown trout Salmo trutta have been introduced into aquatic ecosystems throughout the western United States and have been implicated in the extirpation of many native cutthroat trout Oncorhynchus clarkii populations. We document patterns of size-at-age among multiple populations of brown trout and cutthroat trout in allopatry and sympatry. Comparisons were based on data from 48 allopatric populations ( 9 brown trout and 39 cutthroat trout) and 2 sympatric populations gathered from published reports and field collections. Brown trout are significantly larger than same-age cutthroat trout at all ages in both sympatry and allopatry. Size-at-age was also significantly negatively influenced with increasing latitude and elevation. The size-at-age for both species is reduced when in sympatry, but the reduction is more pronounced for brown trout. Cutthroat trout may be able to persist in the presence of brown trout in these instances because of the limited competitive ability of brown trout due to the reduced size, which may be a result of suboptimal conditions of the habitat. The fact that brown trout are unable to exclude cutthroat trout when growth is restricted suggests that size is an important mechanism of competitive exclusion of cutthroat trout by brown trout.
\end{abstract}

KEY WORDS: Otoliths $\cdot$ Size-at-age $\cdot$ Introduced species $\cdot$ Competitive exclusion $\cdot$ Sympatry

\section{INTRODUCTION}

Competitive exclusion is often invoked to explain the decline of native cutthroat trout after introduction of brown trout (McHugh \& Budy 2005, 2006); however, the underlying mechanisms of competitive interactions are not completely understood (Fausch 1988). Although strong competitive interactions may be relatively rare and somewhat temporary in coevolved natural communities, when species are introduced into systems where similar species already occur, strong competition is likely to occur (Losos et al. 1993). Competition is expected to result in niche partitioning and/or exclusion of one species (Losos 2000, Grant \& Grant 2006). In the case of niche partitioning, individuals may switch to utilization of poorer quality habitat or resources for which there is less competition. If species are able to persist in such a situation this will eventually result in character displacement in which the differences between species become accentuated through adaptation. However, if the lower quality habitat is insufficient to sustain a species, or the species is unable to exploit other resources, then the weaker species will eventually be extirpated or excluded from the site.

Body size is often an important factor in determining the outcome of competitive interactions. In streamdwelling salmonids, larger individuals typically dominate both intra- and inter-specific interactions (Fausch 1984, Taniguchi et al. 1998). They occupy feeding locations with the best access to resources and the least exposure to predatory risk (Rosenfeld \& Boss 2001, 
Taniguchi et al. 2002). Relatively small size differences, e.g. $20 \%$ of biomass, can facilitate eviction of smaller individuals from higher quality feeding territories in young trout (Johnsson et al. 1999). Limited resource availability often results in reduced growth and relatively small size-at-age in fishes (Jones 1986), which may act as a negative feedback loop for competitively inferior individuals or species.

Cutthroat trout Oncorhynchus clarkii populations have declined throughout much of their range (Behnke 1992, Kruse et al. 2000), and several subspecies are considered by state and federal agencies to be threatened or endangered within the USA (Quist \& Hubert 2004). Although cutthroat trout are often considered a headwater species, the species historically inhabited a variety of habitats throughout many western drainages, including lakes and relatively low elevation areas (Quist \& Hubert 2004), but their range has been drastically restricted for several reasons. Interaction with non-native salmonids is one of the main causes of decline and range restriction of cutthroat trout (Allendorf \& Leary 1988, Young 1995, Dunham et al. 2002, Peterson et al. 2004).

Brown trout Salmo trutta have been introduced widely in the western USA, often on top of native cutthroat trout populations (Fuller et al. 1999). In general, this species is relatively similar in habitat use and diet to native cutthroat trout (Dare \& Hubert 2003, McHugh et al. 2008) and, in most introduction cases, the cutthroat trout are extirpated (Behnke 1992, Young 1995), especially in the lower reaches of the stream system (Bozek \& Hubert 1992).

We document patterns of size-at-age among multiple populations of brown trout and cutthroat trout in allopatry and sympatry to explore the role of body size in competitive interactions between these 2 salmonid species. If size is an important determinant of the outcome of inter-specific interactions between brown trout and cutthroat trout, then in sympatric populations the differences in size-at-age between species should be smaller relative to comparison among allopatric populations. If body size is not an important mechanism of competitive interactions between these 2 species, then we would expect no clear relationship between patterns of body size in allopatry versus sympatry. By comparing multiple populations, we provide a general test of predictions that is not dependent on conditions in any particular location.

\section{MATERIALS AND METHODS}

To compare size-at-age between sympatric and allopatric populations of brown trout and cutthroat trout we gathered age-growth curves from published reports and field collections. We attempted to minimize the effect of potentially confounding factors on size and growth by only selecting data from published reports that contained (1) at least 3 age classes, (2) stream or small river habitat, (3) wild inland populations to avoid the inclusion of sea run individuals, and (4) size-at-age estimates based on back-calculations. These data only included populations of both species within the historical range of cutthroat trout in the Rocky Mountain Region of the western USA (Table 1). Allopatric brown trout populations consisted of data from journal reports and field data ( 1 and 8 pop-

Table 1. Summary of citations used for comparison of size-at-age for brown trout Salmo trutta and subspecies of cutthroat trout Oncorhynchus clarkii. The number of sites indicates how many unique locations were reported in the original reference. Only size at ages 1 to 5 were used in the analysis

\begin{tabular}{|c|c|c|c|c|c|c|}
\hline Source & Species & No. of sites & State & Type & Max. age (yr) & $\mathrm{N}$ \\
\hline Belk et al. (2009) & O. c. pleuriticus & 7 & Utah & Otolith & 5 & 350 \\
\hline Bishop (1955) & S. trutta & 1 & Montana & Scale & 7 & 1271 \\
\hline Bjorn (1957) & O. c. lewisi & 15 & Idaho & Scale & 5 & 524 \\
\hline Fleener (1952) & O. c. utah & 1 & Utah & Scale & 3 & 234 \\
\hline Fraley \& Shepard (2005) & O. c. lewisi & 1 & Montana & Otolith & 8 & 843 \\
\hline Johnson (1963) & O. c. lewisi & 2 & Montana & Scale & 6 & 665 \\
\hline Kruse et al. (1997) & O. c. bouvieri & 12 & Wyoming & Otolith & 6 & 259 \\
\hline Platts (1958) & O. c. utah & 1 & Utah & Scale & 4 & 166 \\
\hline \multirow[t]{4}{*}{ Present study } & S. trutta & 8 & Utah & Otolith & 6 & 265 \\
\hline & O. c. pleuriticus ${ }^{\mathrm{a}}$ & 1 & Utah & Otolith & 6 & 14 \\
\hline & O. c. utah & 1 & Utah & Otolith & 6 & 48 \\
\hline & S. trutta ${ }^{\mathrm{a}}$ & 2 & Utah & Otolith & 8 & 63 \\
\hline
\end{tabular}


ulations, respectively; Table 1) from 8 drainages within the USA. The population from the published report was located in Montana (Bishop 1955) (Fig. 1). Field data for allopatric brown trout were collected from 8 locations in Utah: Diamond Fork, Huntington Creek, Lower Fish Creek, Mammoth Creek, Provo River (2 locations), Strawberry River, and Weber River (Fig. 1). Allopatric brown trout populations in this analysis ranged in latitude from $\sim 38^{\circ}$ to $\sim 47^{\circ} \mathrm{N}$ latitude and between 1060 and $2580 \mathrm{~m}$ in elevation.

Data from 39 allopatric cutthroat trout populations (from 6 drainages) from published journal reports were included in the analysis (Table 1). Populations included Bonneville cutthroat Oncorhynchus clarkii utah, Colorado River cutthroat $O$ clarkii pleuriticus, Yellowstone cutthroat $O$. clarkii bouvieri, and westslope cutthroat $O$. clarkii lewisi, located in Idaho, Montana, Utah, and Wyoming, and ranged in latitude from $\sim 40^{\circ}$ to $\sim 49^{\circ} \mathrm{N}$ and between 750 and $3119 \mathrm{~m}$ in elevation.

Although brown trout have been stocked in hundreds of locations where cutthroat trout were native,

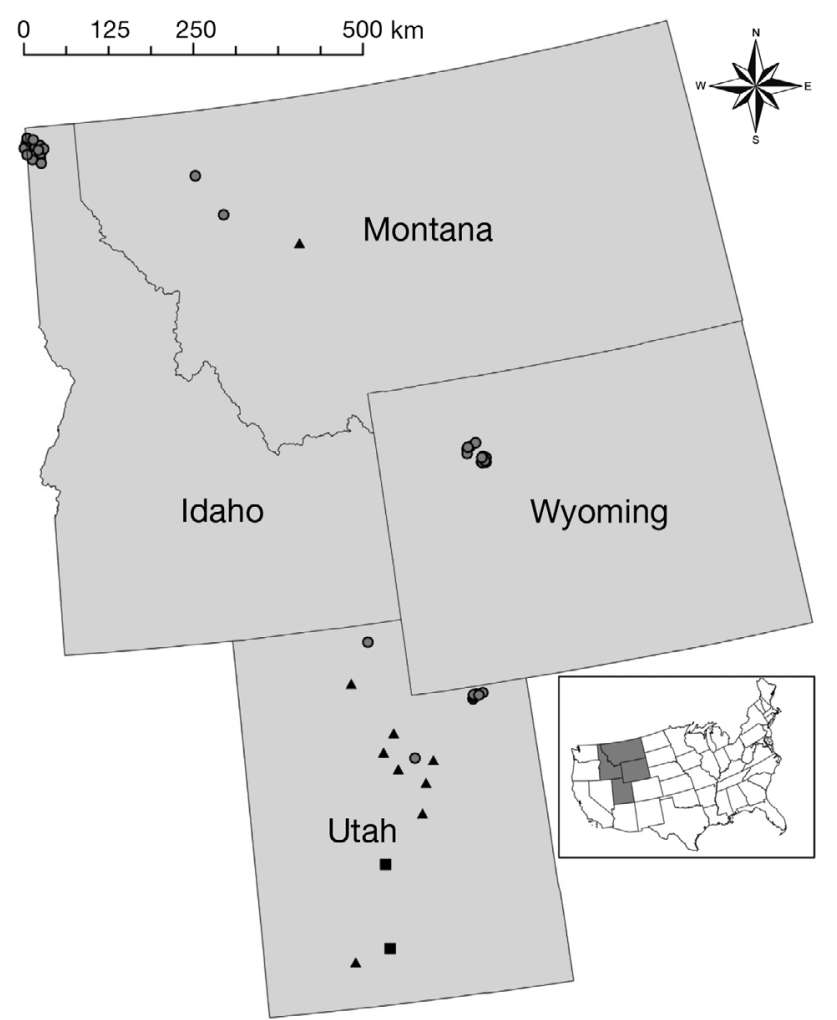

Fig. 1. Map of North America indicating the sites of allopatric brown trout Salmo trutta $(\mathrm{N}=9, \mathbf{\Delta})$ and allopatric cutthroat trout Oncorhynchus clarkii $(\mathrm{N}=39,0)$ populations and the 2 sympatric populations (ם) used for comparison in this study sympatric locations where both species persist appear to be rare. We found no published reports of growth and size-at-age of brown trout and cutthroat trout in sympatry. For comparison, we collected growth data from 2 locations where the species occur in sympatry. The first site was in the upper reaches of Lost Creek, a tributary of the Sevier River located in the eastern Great Basin region of central Utah. The second was in the upper reaches of Pine Creek, a tributary of the Escalante River in the Colorado River drainage of southcentral Utah. A third site of sympatry, Sixth Water Creek, a tributary of the Spanish Fork River located in the Great Basin region of central Utah, was assessed but subsequently excluded from the analysis because the cutthroat trout were hatchery-reared, which created anomalies in growth patterns; these fish were nearly double the size of other cutthroat trout at age 1 . In the 2 selected locations brown trout densities were approximately double those of cutthroat trout. Cutthroat trout in Lost Creek were the Bonneville subspecies, whereas those in Pine Creek were Colorado River cutthroat trout.

Sympatric sites were located at higher average elevations $(2325 \mathrm{~m})$ than allopatric sites $(1894 \mathrm{~m})$, and average elevation of allopatric cutthroat trout populations $(1910 \mathrm{~m})$ was higher than allopatric brown trout populations $(1835 \mathrm{~m})$. The average latitude of sympatric populations $\left(38.289^{\circ} \mathrm{N}\right)$ was farther south than averages for both allopatric cutthroat and brown trout populations $\left(45.294^{\circ}\right.$ and $40.796^{\circ} \mathrm{N}$, respectively).

Backpack electro-fishing gear was used to collect fish in all field locations with the exception of Pine Creek where trout were salvaged from a removal project conducted by the Utah Division of Wildlife Resources in September 2001. Fish were euthanized using a lethal dose of MS-222 and frozen until measurements of length (SL, mm) were taken.

For determination of age and growth patterns we removed otoliths (sagittae), which were then mounted on a glass slide with cyanoacrylate-based adhesive. We used a lapidary grinder (Struers model Dap-7, 500 and 1200 grit silicon carbide) to thin the posterior surface and a dissecting microscope (Wild Leica M3C) at $12 \times$ or $24 \times$ magnification to count annuli. Annuli on otoliths have been validated as true annuli for streamdwelling cutthroat trout (Kruse et al. 1997, Belk et al. 2009) and brown trout (D. Shiozawa unpubl. data).

We used Sigma Scan Pro (Jandel Scientific) to measure annual increments from digital images of the otolith along the longest axis of the otolith. Length-atage was back-calculated using the modified FraserLee method (Campana 1990): 


$$
L_{X}=L_{\mathrm{o}}+\left(L_{\mathrm{c}}-L_{\mathrm{o}}\right)\left(R_{\mathrm{X}}-R_{\mathrm{o}}\right) /\left(R_{\mathrm{c}}-R_{\mathrm{o}}\right)
$$

where $L_{X}$ is estimated standard length at age $X_{1} L_{0}$ is estimated standard length at swim-up, $L_{\mathrm{c}}$ is standard length at capture, $R_{x}$ is otolith radius at age $x_{1} R_{\mathrm{o}}$ is estimated otolith radius at swim-up, and $R_{\mathrm{C}}$ is otolith radius at capture.

Some lengths in the literature were reported as fork length (FL) or total length (TL), so we applied a conversion factor taken from Carlander (1969) to standardize all measurements to SL: for cutthroat trout $\mathrm{SL}=0.87 \mathrm{TL}=0.95 \mathrm{FL}$, and for brown trout $\mathrm{SL}=$ $0.87 \mathrm{TL}=0.90 \mathrm{FL}$. An average SL for ages 1 to 5 was calculated for locations from field collections or from reported values in published reports (when available) for inclusion in the analyses.

We used a linear mixed-effects model analysis of covariance (Pinheiro \& Bates 2000). Analyses were performed using the nlme library (Pinheiro et al. 2007) in R (R Core Development Team 2008) using the maximum likelihood method of estimation. The model included location type (allopatric or sympatric) and species (brown trout or cutthroat trout) as fixed factors, age (1 to 5 yr) as a continuous factor, and average SL at each age as the response variable. The model also included a quadratic term on age $\left(\mathrm{age}^{2}\right)$ to incorporate the slight decrease in growth rates as fish aged. No single environmental characteristic was reported in published reports in a standard way that would allow for inclusion in the analysis. However, to better address site variation that may confound results we included site latitude and elevation as covariates in the analysis. For data from published reports which did not explicitly report elevation, an average elevation was used from the range of probable site locations along the stream gradient based on site descriptions in the report. Age values were adjusted such that the $y$-intercept was at age 1 .

To further account for potentially important, but undocumented variation at each site that may affect growth (e.g. environmental factors) we included location or site as a random variable, and allowed for unique intercepts (likelihood ratio $[\mathrm{LR}]=8.0$, $\mathrm{df}=2, \mathrm{p}=0.02)$ and slopes ( $\mathrm{LR}=180$, $\mathrm{df}=2, \mathrm{p}<0.001$ ) for each location. To account for the probable correlation among closely situated locations, site was also nested within drainage, which we included as a random variable in the model and allowed each to have a unique intercept $(\mathrm{LR}=$ $24.8, \mathrm{df}=1, \mathrm{p}<0.001$ ). Weighting of within-group variances for allopatric populations (weight $=1$ ) and sympatric populations (weight $=0.62$ ) were modeled ( $\mathrm{LR}=6.0, \mathrm{df}=1, \mathrm{p}=0.01$ ) differently to account for heteroscedasticity. Likewise, the within-group correlation structure was specified as continuous autoregressive $(\operatorname{corAR}(1), \mathrm{phi}=0.53, \mathrm{LR}=18.1, \mathrm{df}=1, \mathrm{p}<$ 0.001 ) given the autocorrelated nature of size-at-age estimates. Random effect covariance was modeled with a general positive-definite matrix with no additional structure.

In addition to the main effects, the full model also included all possible 2-way interactions between population type and species and the other main effects, and a 3-way interaction among population type, species, and age (Table 2). Interactions between species and age $(p<0.001)$ and species and latitude $(p=0.02)$ were retained in the reduced model due to their significant contribution to explanation of the variation (Table 3). All other interactions were non-significant $(p>0.20)$, and were excluded from the reduced model, with the exception of population type by species $(p=0.20)$ and population type by age interactions $(p=0.30)$, which were retained due to the significant 3-way interaction between population type, species and age $(p<0.001)$. This reduced model was preferable to the full model based on Akaike's Information Criterion (1727 and

Table 2. Summary of the full model of repeated measures mixed model analysis of variance including species (brown trout and cutthroat trout) population type (allopatric or sympatric), age (1 to $5 \mathrm{yr}$ ), and age ${ }^{2}$ as fixed effects, latitude (degree minutes) and elevation $(\mathrm{m})$ as covariates, drainage and stream as random effects, and mean population size-at-age (standard length) as the response variable

\begin{tabular}{|lccccc|}
\hline Factor & Coefficient & SE & df & $F$ & $p$ \\
\hline Intercept & 388.7 & 125.5 & 1,162 & 703.3 & $<0.001$ \\
Population Type - sympatric & -28.0 & 59.6 & 1,12 & 6.9 & 0.02 \\
Species - cutthroat trout & -25.8 & 143.1 & 1,162 & 291.2 & $<0.001$ \\
Age & 73.0 & 3.8 & 1,162 & 723.1 & $<0.001$ \\
Age & -3.8 & 0.3 & 1,162 & 189.8 & $<0.001$ \\
Latitude & -5.9 & 2.7 & 1,32 & 24.4 & $<0.001$ \\
Elevation & -0.2 & 0.01 & 1,32 & 3.4 & 0.08 \\
Population Type $\times$ Species & 20.2 & 12.0 & 1,162 & 0.97 & 0.33 \\
Population Type $\times$ Age & -20.9 & 8.5 & 1,162 & 1.07 & 0.30 \\
Population Type $\times$ Latitude & 8.1 & 24.0 & 1,12 & 0.05 & 0.819 \\
Population Type $\times$ Elevation & -0.01 & 0.03 & 1,12 & 0.08 & 0.79 \\
Species $\times$ Age & -18.7 & 4.1 & 1,162 & 13.6 & 0.028 \\
Species $\times$ Latitude & 0.15 & 3.2 & 1,162 & 2.8 & 0.097 \\
Species $\times$ Elevation & -0.01 & 0.01 & 1,162 & 1.5 & 0.22 \\
Population Type $\times$ Species $\times$ Age & 14.4 & 4.3 & 1,162 & 11.2 & 0.001 \\
\hline
\end{tabular}



analysis of variance including species (brown trout and cutthroat trout), population type (allopatric or sympatric), age (1 to $5 \mathrm{yr}$ ), and age $^{2}$ as fixed effects, latitude (degree minutes) and elevation (m) as covariates, drainage and stream as random effects, and mean population size-at-age (standard length) as the response variable. Non-significant terms in the full model (Table 2) have been deleted
Table 3. Summary of the reduced model of repeated measures mixed model

\begin{tabular}{|lccccc|}
\hline Factor & Coefficient & SE & df & $F$ & $\mathrm{p}$ \\
\hline Intercept & 492.4 & 90.9 & 1,163 & 811.2 & $<0.001$ \\
Population Type - sympatric & -52.8 & 11.1 & 1,13 & 20.8 & $<0.001$ \\
Species - cutthroat trout & -205.5 & 73.9 & 1,163 & 453.9 & $<0.001$ \\
Age & 72.3 & 3.9 & 1,163 & 732.8 & $<0.001$ \\
Age & -4.1 & 0.4 & 1,163 & 117.8 & $<0.001$ \\
Latitude & -8.1 & 2.0 & 1,32 & 26.5 & $<0.001$ \\
Elevation & -0.02 & 0.01 & 1,32 & 2.9 & 0.099 \\
Population Type $\times$ Species & 29.1 & 11.0 & 1,163 & 1.64 & 0.20 \\
Population Type $\times$ Age & -21.0 & 8.3 & 1,163 & 1.07 & 0.30 \\
Species $\times$ Age & -18.8 & 4.1 & 1,163 & 20.9 & $<0.001$ \\
Species $\times$ Latitude & 4.1 & 1.8 & 1,163 & 5.5 & 0.02 \\
Population Type $\times$ Species $\times$ Age & 15.2 & 4.3 & 1,163 & 13.0 & $<0.001$ \\
\hline
\end{tabular}

their sympatric conspecifics (Fig. 2), and brown trout exhibited greater growth than cutthroat trout. The model predicted a smaller difference between sympatric cutthroat trout and allopatric cutthroat trout than the difference between allopatric and sympatric brown trout populations. At a given age, the modeled length of sympatric brown trout was, on average, $54 \%$ of allopatric brown trout. However, the predicted size-at-age of sympatric cutthroat trout was $75 \%$ of their allopatric conspecifics.

Estimated growth was significantly affected by latitude $(\mathrm{p}<0.001)$ and marginally by elevation ( $p=0.10)$. Growth declined $8.1 \mathrm{~mm}$ for every degree of latitude north and declined $22.6 \mathrm{~mm}$ for every $1000 \mathrm{~m}$ increase in 1750, respectively) and likelihood ratio test $(\mathrm{LR}=$ 18.6, $\mathrm{df}=2, \mathrm{p}<0.001$ ). Estimates are based on this reduced model.

\section{RESULTS}

The greatest growth was found in allopatric brown trout which were more than double the size of the group with the lowest growth; sympatric cutthroat trout (Fig. 2). Allopatric populations were larger than

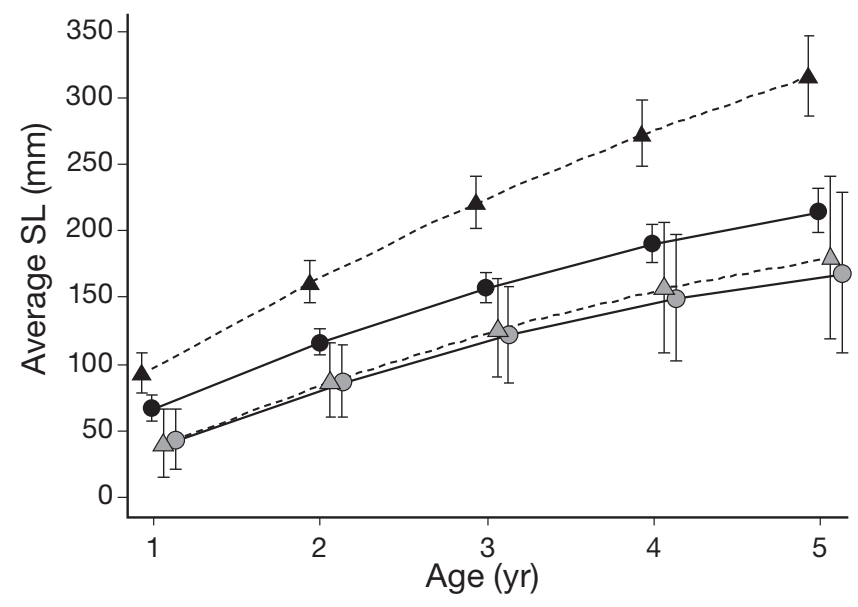

Fig. 2. Least-square means of size-at-age $(\mathrm{SL}=$ standard length) for allopatric $(\boldsymbol{\Delta})$ and sympatric $(\triangle)$ brown trout Salmo trutta populations and allopatric $(\bullet)$ and sympatric $(\bigcirc)$ cutthroat trout Oncorhynchus clarkii populations within North America, as predicted by a linear mixed model analysis of variance calculated at mean elevation $(1933 \mathrm{~m})$ and mean latitude $\left(43.77802^{\circ} \mathrm{N}\right)$. Error bars indicate $95 \%$ CI. Values on the $x$-axis have been 'jittered' for clarity elevation (Table 3). However, predicted size-at-age of cutthroat trout was approximately $4.1 \mathrm{~mm}$ greater for every degree of latitude compared to brown trout.

\section{DISCUSSION}

Brown trout have successfully invaded numerous habitats throughout the western USA and have often replaced the native cutthroat trout; however, the proximal mechanism of brown trout dominance and exclusion of cutthroat trout is largely unknown (McHugh \& Budy 2006). Our results provide indirect evidence that size-based interactions may be an important component of this process. Brown trout sympatric with cutthroat trout are smaller than their allopatric conspecifics. Either the co-existence and coincident competition with cutthroat trout has produced smaller individuals, or smaller brown trout, resulting from environmental conditions for example, were not sufficiently competitively dominant over cutthroat trout to exclude them entirely. If the latter, this suggests that where brown trout have excluded cutthroat trout, size-based competitive interactions is a component of the mechanism.

Size is not the only mechanism for individuals to exert a competitive advantage (Brodman 1999, Bystrom \& Garcia-Berthou 1999, Laurila 2000), but it often strongly influences intra- and inter-specific competitive outcomes (Reques \& Tejedo 1996, Robertson 1996), especially when the interaction is direct, i.e. interference competition. In stream-dwelling salmonids, larger individuals typically dominate both intra- 
and inter-specific interactions (Fausch 1984, Taniguchi et al. 1998) and occupy locations with the best access to resources or the least exposure to predatory risk (Rosenfeld \& Boss 2001, Taniguchi et al. 2002).

Environmental factors may also influence or mediate competitive interactions between species (Fausch 1989) as even very similar species may possess different requirements for optimum conditions. Gradients in abiotic conditions across the longitudinal extent of streams can produce species zonation (Rahel \& Hubert 1991, Bozek \& Hubert 1992, McHugh \& Budy 2005) where the spatial distribution of species is related to the physiological tolerances of the species and the distribution of suitable habitat (Hearn 1987). The competitive ability of individuals in sub-optimal habitat conditions may be affected, especially if environmental conditions produce restricted body size. For example, brook char Salvelinus fontinalis were competitively dominant over Colorado cutthroat trout at warmer temperatures $\left(20^{\circ} \mathrm{C}\right)$ under laboratory conditions, but neither species displayed a significant advantage over the other under cooler water temperatures $\left(10^{\circ} \mathrm{C}\right)$ (De Staso \& Rahel 1994). Similar heterogeneous competitive interactions associated with temperature (Baltz et al. 1982, Reeves et al. 1987) and water velocity (Cunjak \& Green 1984, De Staso \& Rahel 1994) have been documented. However, McHugh \& Budy (2005) concluded that outcomes of in situ competitive interactions between brown trout and cutthroat trout did not appear to be mediated by temperature across a range of mean temperatures from 8.1 to $13.9^{\circ} \mathrm{C}$. Habitat structure, e.g. pools and riffles, were also observed to affect the mode of competitive interaction between Atlantic salmon Salmo salar and brook char (Rodriguez 1995). Competition within riffles was apparently exclusively exploitative, with salmon dominating, but within pools both exploitative and interference competition occurred with the outcome dependent on density. Intrinsic behavioral differences, such as aggressiveness (Wang \& White 1994), may also play a role. Our results potentially reflect brown trout inhabiting sub-optimal habitat and thus incompletely dominating cutthroat trout due to reduced ability given restricted growth (Magoulick \& Wilzbach 1998, Taniguchi et al. 1998).

Broadly speaking, several factors strongly influence salmonid growth, including temperature, trophic status, population density, and latitude (Elliott et al. 1995, Jensen et al. 2000, Valiente et al. 2007). However, a review of the applicability of Bergmann's rule (i.e. a positive relationship between latitude and body size) for 18 species of freshwater fish, including
18 populations of cutthroat trout, concluded that no significant evidence of an increasing trend existed for any of the species examined (Belk \& Houston 2002). Nevertheless, we expect a large amount of variation in our data is due to unique site characteristics; however, quantification of such variables is difficult given the differences in reporting. Inclusion of location nested within drainage in the model as random effects captures a portion of site-specific variation or correlation among sites within drainages due to environmental heterogeneity. Sympatric sites were at higher elevations $(2325 \mathrm{~m})$ than allopatric sites $(1894 \mathrm{~m})$, but at lower latitudes. The possibility remains that our results are confounded by these factors. However, given that values used in our analysis were means from presumed representative samples, we expect that the sampling distribution of the means will tend to closely reflect the true population distribution, and therefore reduce bias in our analysis (Zar 1999).

Additionally, sample sizes for sympatric populations were particularly limited in this analysis, producing strongly unbalanced data. However, natural occurrence of these species in sympatry is apparently extremely rare; therefore, these data likely represent a noteworthy portion of all such instances. Furthermore, too often rare instances or outliers in data are ignored because sufficient data are lacking to perform rigorous analysis or because such data add 'unwanted' noise in the analysis (Gaines \& Denny 1993, Gotelli \& Ellison 2004). Rare events may provide critical insight into processes by providing a backdrop against which the norm can be evaluated.

Brown trout have an inherent size advantage over cutthroat trout in North America, which is maintained in sympatry. Initially, the size difference between brown trout and cutthroat trout probably results from the difference in spawning timing. Fall-spawning brown trout larvae hatch earlier in the year compared to spring-spawning cutthroat trout larvae, and likely utilize this head start to out-compete same-aged cutthroat trout. Brown trout increase this size advantage over cutthroat trout with higher growth rates. This enables brown trout to transition to piscivory sooner than same-aged cutthroat trout (Quist \& Hubert 2004, McHugh et al. 2008) thereby further increasing the growth disparity, and potentially introducing predatory interactions on top of competitive interactions.

Although brown trout have an inherent size advantage over cutthroat trout, the fact that cutthroat trout are able to persist when brown trout are smaller provides insight into the type of interactions between these 2 species. If the reduced growth 
rates of brown trout in these instances are a result of competitive interactions with cutthroat trout, this suggests that this species may be less adapted than cutthroat trout to exploit secondary resources when competitive interactions cause resource partitioning. In a similar system, brook char utilized allocthonous food sources to a much higher degree when in sympatry with Atlantic salmon than in allopatry (Mookerji et al. 2004). In contrast, when brook char and bull char were held in situ under resource limited conditions, no apparent habitat partitioning or differences in foraging habitat were observed when compared with allopatric bull char; however, brook char maintained a growth dominance and exhibited significantly higher growth rates (Gunckel et al. 2002).

A more plausible explanation is that growth patterns of brown trout from sub-optimal conditions have restricted these individuals in size. Even though brown trout are often introduced into areas where competition is likely with cutthroat trout, this species frequently invades successfully. It has been proposed that successful invasion of aquatic environments is less dependent on biotic resistance by the community being invaded than on abiotic conditions, particularly extremes in the hydrologic regime such as high flow events (Moyle \& Light 1996). Species that are adapted to similar hydrologic regimes as the area being invaded are expected to have a higher probability of invasion success. In addition, Moyle \& Light (1996) assert that the probability of a successful invasion increases if the environment has had human disturbance, if the invading species is a top predator or omnivore, or if the native population has been recently depleted or disrupted. Smaller brown trout may not be as competitively dominant over cutthroat trout, which are then able to maintain a presence in the system. If this is the case, it suggests that size is an important factor in the instances where brown trout have been able to exclude cutthroat trout, although this does not provide direct evidence for this conclusion.

Investigation of these apparently rare occurrences of sympatry of cutthroat trout and brown trout can provide unique insights into the interactions of these species. Establishing whether niche partitioning is occurring or whether the species are simply more competitively balanced will also further clarify our understanding of both dynamics in sympatry.

Acknowledgements. We thank D. Hepworth, D. Jorgensen, and S. Belk for help with sample collection. The State of Utah Division of Wildlife Resources provided collecting permits, funding, and assisted with collection of fish from Sixth Water Creek. Brigham Young University provided additional funding.

\section{LITERATURE CITED}

Allendorf F, Leary RF (1988) Conservation and distribution of genetic variation in a polytypic species, the cutthroat trout. Conserv Biol 2:170-184

Baltz DM, Moyle PB, Knight NJ (1982) Competitve interactions between benthic stream fishes, riffle sculpin, Cottus gulosus, and speckled dace, Rhinichthys osculus. Can J Fish Aquat Sci 39:1502-1511

Behnke RJ (1992) Native trout of western North America. Am Fish Soc Monogr 6

Belk MC, Houston DD (2002) Bergmann's rule in ectotherms: a test using freshwater fishes. Am Nat 160: 803-808

Belk MC, McGee MN, Shiozawa DK (2009) Effects of elevation and genetic introgression on growth of Colorado River cutthroat trout. West N Am Nat 69:56-62

$>$ Bishop CG (1955) Age, growth, and condition of trout in Prickely Pear Creek, Montana. Trans Am Microsc Soc 74: 134-145

Bozek MA, Hubert WA (1992) Segregation of resident trout in streams as predicted by three habitat dimensions. Can J Zool 70:886-890

Brodman R (1999) Food and space dependent effects during the interactions of two species of larval salamanders. J Freshw Ecol 14:431-437

> Bystrom P, Garcia-Berthou E (1999) Density dependent growth and size specific competitive interactions in young fish. Oikos 86:217-232

Campana SE (1990) How reliable are growth back-calculations based on otoliths? Can J Fish Aquat Sci 47: 2219-2227

Carlander KD (1969) Handbook of freshwater fishery biology. Iowa State University Press, Ames

Cunjak RA, Green JM (1984) Species dominance by brook trout in a simulated stream environment. Trans Am Fish Soc 113:737-743

Dare MR, Hubert WA (2003) Use of similar habitat by cutthroat trout and brown trout in a regulated river during winter. Northwest Sci 77:36-45

- De Staso J III, Rahel FJ (1994) Influence of water temperature on interactions between juvenile Colorado River cutthroat trout and brook trout in a laboratory system. Trans Am Fish Soc 123:289-297

> Dunham JD, Adams SB, Schroeter RE, Novinger DC (2002) Alien invasions in aquatic ecosystems: toward an understanding of brook trout invasions and potential impacts on inland cutthroat trout in western North America. Rev Fish Biol Fish 12:373-391

- Elliott JM, Hurley MA, Fryer RJ (1995) A new, improved growth model for brown trout, Salmo trutta. Funct Ecol 9: 290-298

Fausch KD (1984) Profitable stream positions for salmonids: Relating specific growth rate to net energy gain. Can J Zool 62:441-451

Fausch KD (1988) Tests of competition between native and introduced salmonids in streams: What have we learned? Can J Fish Aquat Sci 45:2238-2246

Fausch KD (1989) Do gradient and temperature affect distribution of, and interactions between brook char and other salmonids in streams? Physiol Ecol Jpn 1(Special): 303-322

> Fleener GC (1952) Life history of the cutthroat trout, Salmo clarkii Richardson, in Logan River, Utah. Trans Am Fish Soc 81:235-248

Fraley J, Shepard BB (2005) Age and growth, and movements of westslope cutthroat trout, Oncorhynchus clarkii 
lewisi, inhabiting the headwaters of a wilderness river. Northwest Sci 79:12-21

Fuller PL, Nico LG, Williams JD (1999) Nonindigenous fishes introduced into inland waters of the United States. Am Fish Soc Spec Publ 27

Gaines SD, Denny MW (1993) The largest, smallest, highest, lowest, longest, and shortest: extremes in ecology. Ecology 74:1677-1692

Gotelli NJ, Ellison AM (2004) A primer of ecological statistics, Vol. Sinauer Associates, Sunderland

Grant PR, Grant BR (2006) Evolution of character displacement in Darwin's finches. Science 313:224-226

Gunckel SL, Hemmingsen AR, Li JL (2002) Effect of bull trout and brook trout interactions on foraging habitat, feeding, behavior, and growth. Trans Am Fish Soc 131: 1119-1130

Hearn WE (1987) Interspecific competition and habitat segregation among stream-dwelling trout and salmon: a review. Fisheries (Bethesda, Md) 12:24-31

Jensen AJ, Forseth T, Johnsen BO (2000) Latitudinal variation in growth of young brown trout Salmo trutta. J Anim Ecol 69:1010-1020

Johnson HE (1963) Observations on the life history and movement of cutthroat trout, Salmo clarkii, in Flathead River drainage, Montana. Proc Montana Acad Sci 23: 96-110

> Johnsson JI, Nobbelin F, Bohlin T (1999) Territorial competition among wild brown trout fry: effects of ownership and body size. J Fish Biol 54:469-472

Jones GP (1986) Food availability affects growth in a coral reef fish. Oecologia 70:136-139

Kruse CG, Hubert WA, Rahel FJ (1997) Using otoliths and scales to describe age and growth of Yellowstone cutthroat trout in a high-elevation stream system, Wyoming. Northwest Sci 71:30-38

Kruse CG, Hubert WA, Rahel FJ (2000) Status of Yellowstone cutthroat trout in Wyoming waters. N Am J Fish Manage 20:693-705

Laurila A (2000) Competitve ability and the coexistence of anuran larvae in freshwater rock-pools. Freshw Biol 43: $161-174$

Losos JB (2000) Ecological character displacement and the study of adaptation. Proc Natl Acad Sci 97:5693-5695

Losos JB, Marks JC, Schoener TW (1993) Habitat use and ecological interactions of an introduced and native species of Anolis lizard on Grand Cayman, with a review of the outcome of anole introductions. Oecologia 95: 525-532

> Magoulick DD, Wilzbach MA (1998) Are native brook charr and introduced rainbow trout differentially adapted to upstream and downstream reaches? Ecol Freshw Fish 7: $167-175$

McHugh P, Budy P (2005) An experimental evaluation of competitive and thermal effects on brown trout (Salmo trutta) and Bonneville cutthroat trout (Oncorhynchus clarkii utah) performance along an altitudinal gradient. Can J Fish Aquat Sci 62:2784-2795

McHugh P, Budy P (2006) Experimental effects of nonnative brown trout on the individual- and population-level performance of native Bonneville cutthroat trout. Trans Am Fish Soc 135:1441-1455

McHugh P, Budy P, Theide G, VanDyke E (2008) Trophic relationships of nonnative brown trout, Salmo trutta, and native Bonneville cutthroat trout, Oncorhynchus clarkii utah, in a northern Utah, USA river. Environ Biol Fishes 81:63-75

Mookerji N, Weng Z, Mazumder A (2004) Food partitioning

Editorial responsibility: Hans Heinrich Janssen,

Oldendorf/Luhe, Germany between coexisting Atlantic salmon and brook trout in the Sainte-Marguerite River ecosystem, Quebec. J Fish Biol 64:680-694

Moyle PB, Light T (1996) Fish invasions in California: Do abiotic factors determine success? Ecology 77 : 1666-1670

> Peterson DP, Fausch KD, White GC (2004) Population ecology of an invasion: effects of brook trout on native cutthroat trout. Ecol Appl 14:754-772

Pinheiro JC, Bates DM (2000) Mixed effects models in S \& S-Plus. Springer-Verlag, New York

Pinheiro JC, Bates DM, Debroy S, Sarkar D (2007) nlme: Linear and nonlinear mixed effects models - R package version 3.1-86

Platts WS (1958) Age and growth of cutthroat trout in Strawberry Reservoir, Utah. Utah Academy of Sciences, Arts, and Letters Proceedings 35:101-103

> Quist MC, Hubert WA (2004) Bioinvasive species and the preservation of cutthroat trout in the western United States: ecological social, and economic issues. Environ Sci Policy 7:303-313

R Core Development Team (2008) R: a language and environment for statistical computing. R Foundation for Statistical Computing, Vienna

> Rahel FJ, Hubert WA (1991) Fish assemblages and habitat gradients in a Rocky Mountain-Great Plains stream: biotic zonation and additive patterns of community change. Trans Am Fish Soc 120:319-332

> Reeves GH, Everest FH, Hall JD (1987) Interactions between redside shiner (Richarsonius balteatus) and the steelhead trout (Salmo gairdneri) in western Oregon: the influence of water temperature. Can J Fish Aquat Sci 44: 1603-1613

Reques R, Tejedo M (1996) Intraspecific aggressive behaviour in fire salamader larvae (Salamandra salamandra): the effects of density and body size. Herpetol J 6:15-19

Robertson DR (1996) Interspecific competition controls abundance and habitat use of territorial Caribbean damselfishes. Ecology 77:885-899

Rodriguez MA (1995) Habitat-specific estimates of competition in stream salmonids: a field test of the isodar model of habitat selection. Evol Ecol 9:169-184

> Rosenfeld JS, Boss S (2001) Fitness consequences of habitat use for juveniles cutthroat trout: energetic costs and benefits in pools and riffles. Can J Fish Aquat Sci 58:585-593

Taniguchi Y, Novinger DC, Rahel FJ, Gerow K (1998) Temperature mediation of competitve interactions among three fish species, brook trout, brown trout, and creek chub that replace each other along longitudinal stream gradients. Can J Fish Aquat Sci 55:1894-1901

Taniguchi Y, Fausch KD, Nakano S (2002) Size-structured interactions between native and introduced species: can intraguild predation facilitate invasion by stream salminds? Biol Invasions 4:223-233

Valiente AG, Juanes F, Nunez P, Garcia-Vazquez E (2007) Is genetic variability so important? Non-native salmonids in South America. J Fish Biol 71:136-147

Wang L, White RJ (1994) Competition between wild brown trout and hatchery greenback cutthroat trout of largely wild parentage. N Am J Fish Manage 14:475-487

Young MK (1995) Conservation assessment for inland cutthroat-General Technical Report RM-GTR-256. Rocky Mountain Forest and Range Experimental Station, Forest Service, U.S. Department of Agriculture, Fort Collins

Zar JH (1999) Biostatistical analysis. Prentice Hall, Upper Saddle River

Submitted: November 12, 2010; Accepted: August 29, 2011

Proofs received from author(s): October 29, 2011 